\title{
Study regarding Strength on the Development of Crazing Cracks in Resin Denture Base
}

\author{
by \\ Katsuo TSURUMAKI*
}

\section{Introductory}

The belief has been hitherto held that a denture base which was rectified of its defects will bring about a reduction in strength and some warpage even with an excellent skill on the part of a dentist. Partly because of this belief, studies both basic and clinical with reference to a remedy method have been sadly neglected. The present study attempts at looking into some basic conclusions for a workable remedy of crack defects in the denture base.

\section{Experimental Techniques}

\section{a. Influence of surface treatment in the contact area}

A comparative study of tensile strength was carried out on the four items of 1 ) rinsing with hot water, 2) rinsing of the monomer, 3) erasure of the surface, and 4) erasure of the surface together with the treatment of the monomer.

\section{b. Influence of adhesive materials}

A comparative study of tensile strength was carried out on 1) heat-curing resin, 2) self-curing resin, and 3) the same material with the use of 'Brush on technique'. For the test purpose, the tensile test and bending test were concurrently employed.

As is shown on Fig. 1, a specimen used in the tensile test is $15 \mathrm{~mm}$ wide, $70 \mathrm{~mm}$ long and $3 \mathrm{~mm}$ thick. Another specimen in the bending test is $10 \mathrm{~mm}$ wide, $60 \mathrm{~mm}$ long and $2.5 \mathrm{~mm}$ thick $(3 / 100 \mathrm{~mm})$. They were subjected to the curing process by a routine method, and a weight was added in the center of the test pieces. Intervals for the contact area were $3 \mathrm{~mm}$ for the tensile test and $2 \mathrm{~mm}$ for the bending test respective1y. After the adhesion process, they were polished to the prescribed size. The contact areas were polished to a level plane by means of the carborundum point and no further polishing was effected.

The Amsler Type Universal Test Machine was used for the tensile test and for the bending test a transverse test machine with J.I.S.T. 6501 specifications was employed.

\section{Results}

As is given by Table 1 , there are seen wide differences in the adhesive strengths

\footnotetext{
* 鶴巻克雄: Dept. of Dental Technology, Nihon Univ. School of Dentistry (Director: Prof. Kazuo NAGAI)

The above study was read before the 52 nd Philippine Dental Convention held in Manila Philippine, in May 1960.
} 
Fig. 1. Specimen of Unionized Strength
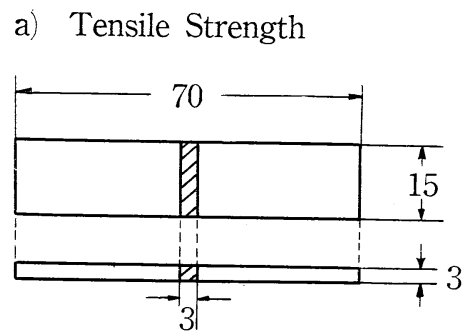

\section{b) Bending Strength}

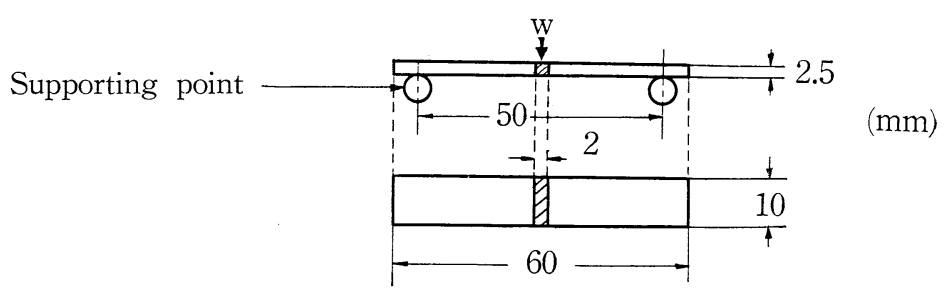

TABLE 1

\begin{tabular}{|c|c|c|c|}
\hline Adhesive (Material) & $\begin{array}{l}\text { Treatment with } \\
\text { Unionized Surface }\end{array}$ & $\begin{array}{c}\text { Tensile Strength } \\
\left(\mathrm{kg} / \mathrm{cm}^{2}\right)\end{array}$ & Fractured Part \\
\hline \multirow{4}{*}{$\begin{array}{l}\text { Heat-Curing Resin } \\
\text { (Acrylic Resin) }\end{array}$} & Wash with Hot Water & 139 & Unionized Part \\
\hline & $\begin{array}{l}\text { Wiping with } \\
\text { Monomer }\end{array}$ & 181 & "I \\
\hline & Trimming & 248 & "1 \\
\hline & $\begin{array}{l}\text { Trimming }+ \text { Wiping } \\
\text { with Monomer }\end{array}$ & 349 & $\begin{array}{l}\text { Middle Part of } \\
\text { Adhesive Material }\end{array}$ \\
\hline
\end{tabular}

of four materials as a result of the surface treatment. Adhesion is found quite inadequate when a material is simply rinsed with hot water or is coated with the monomer. The reason for this is accounted by the thin film of wax which is not entirely removed from its application as a provisional binder and remains on the surface of a material. Therefore, a slight trimming of the remaining wax is effective and is attended by a fairly good result. However, the author suspected some other factor besides the film of wax and so he gave an ample coating of the monomer after the trimming process. As a consequence, an adhesion could be secured almost to an ideal degree.

Table 2 gives the adhesive strengths of various adhesive resins in common use. Of them, the heat-curing resin is found to be possessed of the strongest adhesion. Other adhesives came to fall off the contact areas. However, even if the heat-curing resin is used it is greatly influenced for its adhesive strength by conditions attending the curing. With the use of the self-curing resin some sort of special treatment is found necessary as the strength by itself is very weak (Table 2). Otherwise it will 
TABLE 2

\begin{tabular}{c|c|c}
\hline $\begin{array}{c}\text { Adhesive Materials } \\
\text { (Repair Materials) }\end{array}$ & $\begin{array}{c}\text { Tensile Strength } \\
\left(\mathrm{kg} / \mathrm{cm}^{2}\right)\end{array}$ & Fractured Parts \\
\hline Heat Curing Resin & 349 & Outside of Unionized Part \\
\hline Self-Curing Resin & 142 & $\prime \prime$ \\
\hline $\begin{array}{c}\text { Brush on Technic } \\
\text { (Self-Curing Resin) }\end{array}$ & 101 &
\end{tabular}

Fig. 2. Bending Strength (Acrylic Resin)

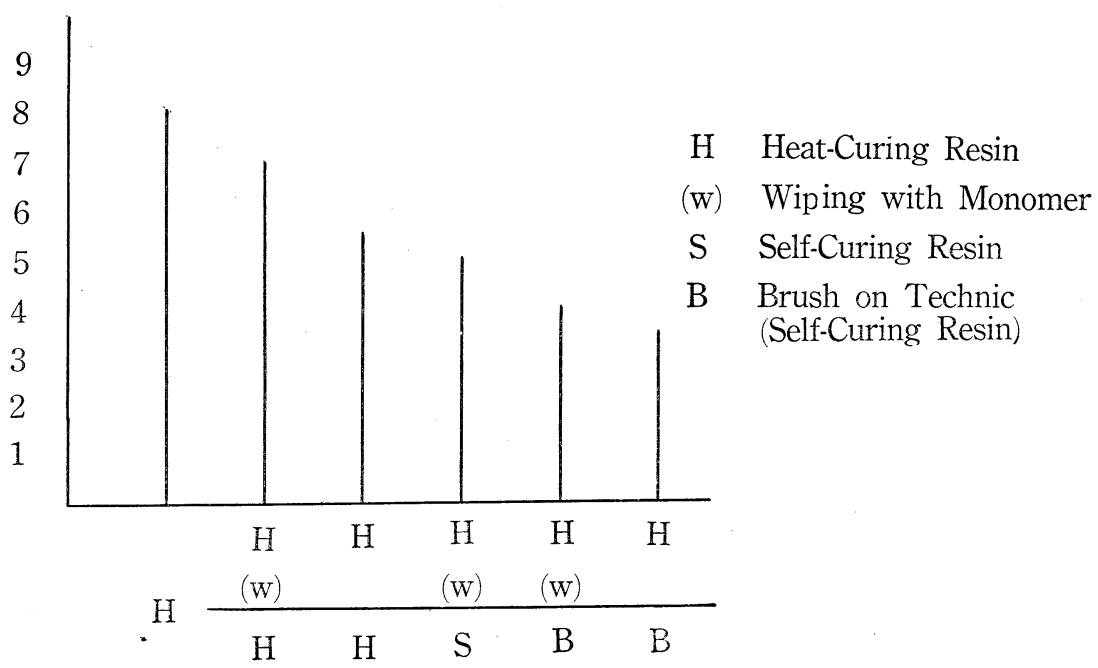

come off. But MIYAZU reports his conclusions that even if some method of special treatment such as the addition of temperature is adopted so as to increase the adhesive strength, these materials will come off sooner or later.

At any rate the following findings have been obtained through a series of these tests. That is to say, in order that we may obtain the maximum adhesion we will have to pay due attention to the trimming treatment of the contact surface, select the heatcuring resin and then carry out the so-called right curing. As far as these conditions prevail, the development of cracks will not constitute a cause to weaken the adhesive strength of a resin material. Examination of the test specimens reveals that the adhesive resins were out in places other than where they came off and this is evidence enough that the strength of an adhesive resin is weaker than that of a denture base in which cracks developed. Results of the bending test are given in Fig. 2 and they are more or less parallel to those of the tensile test.

\section{Conclusions}

The study referred to in the foregoing sections has furnished the following conclusions : 
1. Cracks which develop through the coating of the monomer and which have been eyed with fear hitherto will not weaken the adhesive strength of a resin as far as the adhesion treatment is aimed at. The use of the monomer coating is strongly recommended as a means of enhancing the adhesive strength.

2. When strength is sought in an adhesive material, the selection should be made of the heat-curing resin.

3. The adhesive strength of the self-curing resin is found weak. 